\title{
Energy harvesting maximization by integration of distributed generation based on economic benefits
}

\author{
Tarek A. Boghdady ${ }^{1}$, Samar G. A. Nasser ${ }^{2}$, Essam El-Din Aboul Zahab ${ }^{1}$ \\ ${ }^{1}$ Department of Electrical power Engineering, Faculty of Engineering, Cairo university, Giza, Egypt \\ ${ }^{2}$ Department of Electrical Power Engineering, Institute of Aviation Engineering and Technology (I.A.E.T), Giza, Egypt
}

\begin{tabular}{l} 
Article Info \\
\hline Article history: \\
Received Jan 27, 2021 \\
Revised Dec 19, 2021 \\
Accepted Dec 27, 2021 \\
\hline
\end{tabular}

Keywords:

Distributed generation

Genetic algorithm

Grey wolf optimizer

Particle swarm optimization

Whale optimization algorithm

\begin{abstract}
The purpose of distributed generation systems (DGS) is to enhance the distribution system (DS) performance to be better known with its benefits in the power sector as installing distributed generation (DG) units into the DS can introduce economic, environmental and technical benefits. Those benefits can be obtained if the DG units' site and size is properly determined. The aim of this paper is studying and reviewing the effect of connecting DG units in the DS on transmission efficiency, reactive power loss and voltage deviation in addition to the economical point of view and considering the interest and inflation rate. Whale optimization algorithm (WOA) is introduced to find the best solution to the distributed generation penetration problem in the DS. The result of WOA is compared with the genetic algorithm (GA), particle swarm optimization (PSO), and grey wolf optimizer (GWO). The proposed solutions methodologies have been tested using MATLAB software on IEEE 33 standard bus system.
\end{abstract}

This is an open access article under the CC BY-SA license.

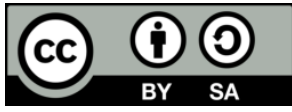

\section{Corresponding Author:}

Tarek A. Boghdady

Department of Electrical Power Engineering, Faculty of Engineering, Cairo University

El Gamma Street, Giza, Egypt

Email: Engtarek82@gmail.com

\section{INTRODUCTION}

In the last few years, society and electric power system utilities have met numerous economic, environmental and technical power quality problems associated with power systems. So, with better energy planning and the use of emerging smart technology, research is now making a great effort to pay attention to the existing infrastructure. One of the most applicable solutions for improving DS performance is the optimum allocation of distributed generation (DG) in the distribution system (DS). As the non-optimal allocation of DG may consequence in an increase in energy loss, lower voltage profile than acceptable boundaries in addition to high expends [1]. If real active power losses are far higher than the normal values, DS companies in Egypt are economically penalized. Or, on the other hand, they gain a good profit [2]. Also, high real active power losses decrease the transmission efficiency to the end user; therefore, its decrease attracted much more attention from distribution companies [3]. Likewise, decreasing the reactive power loss is also objective that should be taken into consideration during DG planning. Thus, reducing the reactive power consumption, diminishing voltage drops and empowering system loadability are one of the most common objectives [4]. Moreover, it aids active power flow through transmission and distribution (T\&D) lines to the end user [3].

The optimal DG size and site supports in decreasing the resistance losses $\left(I^{2} R\right)$, the reactance losses $\left(I^{2} x\right)$ and consequently the voltage drop in the two components (IR and IX) in the DS [2]. Many research objectives in DG planning based on the single objective index (SOI) almost as if it were real power or 
minimizing the energy loss of the DS and not taking note of the merits of the sum of the weighted multiobjectives index (MOI), such as energy loss minimization, voltage profile enhancement and total cost reduction of the DS. A new proposed optimization technique is proposed for location and how to size the DG in DS with a changed loading conditions for minimization of real power loss of the system, is proposed in [5]-[7]. The MOI of performance for DS with DG, which includes a wide range of electric technical problems, is proposed in [8]. The optimal MOI sizing and location of multiple DGS in addition to shunt capacitor banks all together in view of load uncertainty by adjusted particle swarm optimization (PSO) approach from dissimilar power system performances views, is presented in [9].

A technique on empowering the power system parameters systems by selecting the optimally located DG in DS is proposed in [10]. States that the effect that was elevated because of the joining of DG into the present network from different power system performances viewpoints [11]. The objective function contains voltage profile enhancement and power losses minimization using ant colony algorithm, the suggested method was confirmed on IEEE 33-bus test system, the results display a significant lessening in the total power loss and enhanced voltage profiles of all the buses. Correspondingly, allocating of DGS and optimal penetration of solid state fault current limiters (SSFCLs) have been applied [12]-[13]. It was also discovered that adding DG units to the DS decreases the reactive and active power loss and enhance the stability of voltage of the system. PSO has been presented in [14] for penetration of DGS for loss minimization. Several researches motivated in decreasing the system losses neglecting the costs of losses, DGS units' connection and its maintenance. Although particular papers [15]-[18] they took these costs into account, but only concentrated on improving voltage stability without reducing system losses. This paper is providing a complete review on the effect of connecting DG units in the DS. Comprehensive methodology using genetic algorithm is proposed and other methods to determine:

- $\quad$ Optimum size DGs and maximization SOI of transmission efficiency.

- $\quad$ Optimum site DGs and maximization SOI of transmission efficiency.

- $\quad$ Allocation of DGs and maximization SOI of transmission efficiency.

- Allocation of DGs and minimization MOI of reactive power loss (Qloss), voltage deviation (VD) and maximization of transmission efficiency.

- $\quad$ Allocation of DGs and minimization SOI of total cost and maximization of transmission efficiency.

The proposed 33-bus IEEE DS radial algorithms were applied and the results were compared with other techniques. The backward/forward sweep (BFS) method is used here for lateral radial DS power flow analysis because it is simple to implement, flexible, fast, and has extreme accuracy [19]-[20]. The rest of this paper is arranged as follows. Section 2 discusses the problem formulation, while sections 3 present methodology and 4 present simulation results, finally the paper conclusions explained in section 5 .

\section{PROBLEM FORMULATION}

\subsection{Power flow formulation}

The BFS algorithm for Figure 1 measures the power flow estimates. Shows the DS segment, provided that the $\mathrm{N}$ line is linked between the two ' $\mathrm{i}$ ' and ' $\mathrm{j}$ ' buses given. Three measures based on the currents and voltage law of the Kirchhoff are used to evaluate the BFS technique Kirchhoff's current law (KCL) and Kirchhoff's voltage law (KVL), correspondingly. The three stages are: (a) backward sweep, (b) forward sweep, and (c) nodal current analysis. Such measures depend on concourse achievements if the maximum mismatch between voltages is less than the epsilon acceptance provided.

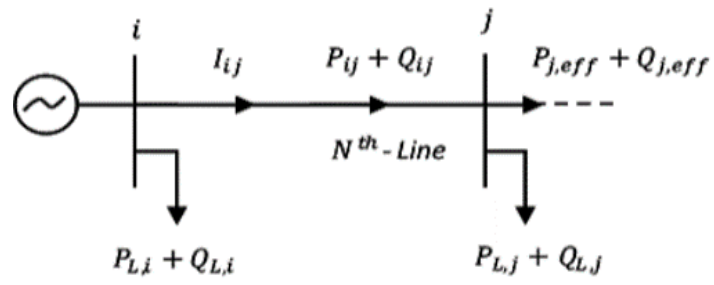

Figure 1. A section of DS

It is easy to estimate the active and reactive power losses for the radial DS after the concourse. The BFS power flow evaluations are presented as: the flow of active ( $\left.P_{-} i j\right)$ and reactive (Q_ij) powers from node ' $\mathrm{i}$ ' to node ' $\mathrm{j}$ ' via branch ' $\mathrm{N}$ ' can be obtained from the latest node in (a) backwards sweep path as: 


$$
\begin{gathered}
P i j=P_{j}^{\prime}+R_{i j} \frac{\left(P_{j}^{\prime 2}+Q_{j}^{\prime 2}\right)}{V_{j}^{2}} \\
Q i j=Q_{j}^{\prime}+X_{i j} \frac{\left({P_{j}^{\prime}}^{2}+{Q_{j}^{\prime}}^{2}\right)}{V_{j}^{2}}
\end{gathered}
$$

where, $P_{i j}^{\prime}=P j+P L j$ and $Q_{i j}^{\prime}=Q j+Q L j \cdot P L j$ and $Q L j$ are loads that are attached at node 'j'. $P_{j}$ and $Q_{j}$ are the active and reactive power flowing from node ' $\mathrm{j}$ '.

The magnitude and angle of voltage at each node are considered in (b) forward direction. take into account a voltage $V i \angle \delta \mathrm{i}$ at node ' $\mathrm{i}$ ' and $V j \angle \delta j$ at node ' $\mathrm{j}$ ', then the (c) the current flowing through the branch 'N' having an impedance, $Z i j=R i j+j X i j$ linked between 'I' and ' $\mathrm{j}$ ' are given as:

$$
\begin{aligned}
& I_{i j}=\frac{(V j \angle \delta j-V j \angle \delta j)}{R i j+j X i j} \\
& I_{i j}=\frac{\left(P_{i}-j Q_{i}\right)}{V j \angle-\delta j}
\end{aligned}
$$

hence from (3) and (4) the bus voltage at 'j' can be calculated as:

$$
V_{j}=\left[V_{i}^{2}-2 *\left(P_{i} R i j+j Q_{i} X i j\right)+\left(R_{i j}^{2}+X_{i j}^{2}\right) * \frac{P_{i}^{2}+Q_{i}^{2}}{V_{i}^{2}}\right]^{0.5}
$$

the magnitude and phase angle equations can be suggested correspondingly in (b) the forward direction to find the voltage and angle of all radial DS nodes. It is possible to present the active and reactive power losses of line ' $\mathrm{N}$ ' between buses ' $\mathrm{i}$ ' and ' $\mathrm{j}$ ' as:

$$
\begin{aligned}
& P_{l o s s(i j)}=R_{i j} \frac{\left(P_{i j}^{2}+Q_{i j}^{2}\right)}{V_{i}^{2}} \\
& Q_{l o s s(i j)}=X_{i j} \frac{\left(P_{i j}^{2}+Q_{i j}^{2}\right)}{V_{i}^{2}}
\end{aligned}
$$

the total active power loss of radial DS can be considered as:

$$
P T_{\text {loss }}=\sum_{j=1}^{N} P_{\text {loss }(i j)}
$$

where ' $N$ ' is the number of branches, $i=1: n$ and ' $n$ ' is the number of buses.

\subsection{Power loss estimation in case of existing DGS units}

Then the power losses within a line sector in Figure 1 when putting DG units in the DS. It is:

$$
\begin{aligned}
& P_{D G, \operatorname{loss}(i j)}=R_{i j} \frac{\left(P_{D G(i j)}^{2}+Q_{D G(i j)}^{2}\right)}{V_{i}^{2}} \\
& P_{D G, T L O S S}=\sum_{j=1}^{N} P_{D G, \operatorname{loss}(i j)}
\end{aligned}
$$

where, $P_{D G, l o s s(i j)}$ and $Q_{D G, l o s s(i j)}$ is the active and reactive power loss when locating DGS between buses ' $i$ ' and ' $j$ ', $P_{D G, T L O S S}$ is the total power loss with locating DGS.

\subsection{Index of power losses}

The total power loss index $\triangle P l D G$ is calculated as the division of total power loss with connecting DGS by the total power loss without connecting DGS and it is presented as:

$$
\Delta P l_{D G}=\frac{P_{D G, T L O S S}}{P_{T L O S S}}
$$

by minimizing, the total power loss in the system reduced by integration DGS. 


\subsection{Voltage deviation index (VDI)}

The VDI can be presented as (12).

$$
V_{D}=\max \left(\frac{V_{1}-V_{i}}{V_{1}}\right), \forall i=1,2, \ldots \ldots \ldots, n
$$

\subsection{DGS cost evaluation}

DS companies are mainly responsible for providing the demand of end user. So that, benefits and costs of DGs site and size in a utility network may be proposed as shown:

- Cost of investment

Investment cost includes DG units cost, investigation fee, DG units installation, preparation of location. It can be presented as:

$$
C_{1}=\sum_{i=1}^{N D G} K_{D G i} * I C_{i}
$$

where, $\mathrm{i}=1,2,3 \ldots \mathrm{NDG}$, no. of DGS that should be located. K_DGi Is the MW capacity of i DG. IC_i is the initial cost of i DG in $\$ / M W$.

- Cost of operation

DG operating cost is mainly depending on DGs operation to produce power for end users can be presented as:

$$
C 2=\sum_{i=1}^{N D G}\left[K_{D G i} * O C_{i}\right] * \Delta T
$$

while, $\mathrm{OC}_{\mathrm{i}}$ is the cost of operation of $\mathrm{i} \mathrm{DG}$ in $\$ / \mathrm{MWh}$ of $\mathrm{i} \mathrm{DG}, \Delta \mathrm{T}$ is the operating hours during a year. And if the inflation rate (IF) and the interest rate (IR), so that the present worth value (PWV) can be signified as:

$$
\beta^{t}=\sum_{t=1}^{n}\left(\frac{1+I F}{1+I R}\right)^{t}
$$

where, $\beta^{t}$ is PWV, $\mathrm{n}$ is the planning period in years. PWV of operating cost in planning year can be considered as:

$$
P W V(C 2)=\sum_{i=1}^{N D G}\left[K_{D G i} * O C_{i}\right] * \Delta T * \beta^{t}
$$

- Maintenance cost

$\mathrm{MC}_{\mathrm{DGi}}$ Can be calculated as (percentage\% of initial cost per year.

\subsection{DGS benefits evaluation}

- Real power demand decreases from DS network

In an energy efficient power system, transmission grid sold its power to DS company to achieve the energy request of end users. DS corporation can resource demand of power with existing of DGS, then obtain lower electrical power from transmission grid. DS company can create a market and sell the energy to the grid as per agreed contract as shown:

$$
B_{1}=\sum_{i=1}^{N D G} K_{D G i} * E P_{G} * \Delta T
$$

while, $\mathrm{EP}_{\mathrm{G}}$ is the price of electricity in $(\$ / \mathrm{KWh})$, and $\Delta \mathrm{T}$ is time segment in which energy is sold to grid. PWV of the generated electricity from DG by the DS company can be considered as shown:

$$
P W V(B 1)=\sum_{i=1}^{N D G} K_{D G i} * E P_{G} * \Delta T * \beta^{t}
$$

- Loss reduction revenue

Economic benefit is the main target of DS company for maximizing the profit. So, the revenue came from the loss reduction in the existence of DGs estimated as:

$$
B_{2}=\sum_{i=1}^{N D G} \Delta \operatorname{LOSS}_{i j} * E P_{G} * \Delta T
$$

$\Delta$ LOSS $_{i j}$ Is the active power loss reduction, when DGs is sited in the network and $\mathrm{EP}_{\mathrm{G}}$ is the electricity price in the grid in $\$ / \mathrm{kWh}$. The PWV of loss reduction revenue in a planned zone can be calculated as: 
$P W V(B 2)=\sum_{i=1}^{N D G} \Delta L O S S_{i j} * E P_{G} * \Delta T * \beta^{t}$

\section{METHODOLGY}

It is commonly known that the MOF is mathematically modeled in order to optimize the obtained benefits of the DG integration into the DS in terms of different indices. These indices importance appears when planning and operation of DG because of their significant impact on the income of utilities', power quality, security, environmental effect and system stability [4]. In our review we have two phases, the first one was maximizing transmission efficiency, minimizing voltage deviation and reactive power loss. The second phase was a single objective function (SOI) to minimize the total cost. The MOF can be stated as the weighted sum of the transmission efficiency (TEI) and the voltage deviation index (VDI) and reactive power loss reduction index (QLI). The weighted summation method is efficient, the development of a strongly nondominated solution that can be used as the initial solution for other approaches is simple and feasible [21]. MOF minimization can be stated from (21):

$$
\begin{aligned}
& \operatorname{Minimize}(M O F)=\min \left[W_{p l} P L I+W_{Q L} Q L I+W_{V D} V D I\right] \\
& W_{p l}+W_{Q L}+W_{V D}=1
\end{aligned}
$$

the reactive power loss reduction $\left(\mathrm{W}_{\mathrm{QL}}\right)$, voltage deviation $\left(\mathrm{W}_{\mathrm{VD}}\right)$. The transmission efficiency are each assigned with different weighting factors according to their importance.

\subsection{Reactive and real power loss indices (QLI, PLI)}

In this approach, the benefits can be achieved when lowering the indices values. The reactive and real power loss indices are well-defined as;

$$
\begin{gathered}
P L I=\frac{P L_{D G}}{P L} \\
Q L I=\frac{Q L_{D G}}{Q L}
\end{gathered}
$$

where, $\mathrm{QL}_{\mathrm{DG}}$ and $\mathrm{PL}_{\mathrm{DG}}$ are the total reactive and real power losses of the DS after presence of DG. QL and $\mathrm{PL}$ are the total reactive and real losses without existing DG in the DS.

\subsection{Voltage deviation index (VDI)}

In this approach, the better network performance can be achieved when this index is much lower. Selecting the proper location of DG improves the voltage profile. This index maybe is used for finding the DG locations taking into consideration the pre-established voltage deviation limit, and also for ensuring the rated voltage concerned for each bus within the allowable limits. Where, V1 is the rated voltage (normallyV1=100\%), ' $\mathrm{n}$ ' is the nodes number and Vi is the bus I voltage. The VDI can be estimated:

$$
V D I=\max \left(\frac{V_{1}-V_{i}}{V_{1}}\right), \forall i=1,2, \ldots \ldots \ldots, n
$$

\subsection{Maximizing profit (MP)}

In a few words, the view point of benefit and cost that have been shown in the previous sections are worked in a one single objective function (SOF) that is expressed below for maximizing the distribution company profit taking into consideration the constraints.

$$
\begin{aligned}
& \text { max profit }=\text { Benefits }- \text { Investments } \\
& \text { Mincost }=\sum_{\mathrm{i}=1}^{\mathrm{NDG}} \mathrm{K}_{\mathrm{DGi}} * \mathrm{EP}_{\mathrm{G}} * \Delta \mathrm{T} * \beta^{\mathrm{t}}+\sum_{\mathrm{i}=1}^{\mathrm{NDG}} \Delta \text { losss } * \mathrm{EP}_{\mathrm{G}}-\sum_{\mathrm{i}=1}^{\mathrm{NDG}} \mathrm{K}_{\mathrm{DGi}} * \text { OCi } \Delta \mathrm{T} * \beta^{\mathrm{t}}- \\
& \sum_{\mathrm{i}=1}^{\mathrm{NDG}}\left[\mathrm{K}_{\mathrm{DGi}} * \mathrm{IC}_{\mathrm{i}} *\left\{1 \mathrm{MC}_{\mathrm{DG}} * \beta^{\mathrm{t}}\right\}\right]
\end{aligned}
$$

\subsection{Solution methodology for multiple DG connecting}

The methodology of connecting for multi DG can be expressed in three stages. The first stage is identifying the optimal DG location, then the optimal DG size and finally by optimizing the optimal placement and size.

Indonesian J Elec Eng \& Comp Sci, Vol. 25, No. 2, February 2022: 610-625 


\subsubsection{Identifying the optimal DG source's location}

This procedure is repetitive for multiple DGs connecting. The starting base system is reformed by considering a fixed optimal DG size at the best locations in the DS configuration (DSC) firstly by injecting a DG unit one-by-one in the DSC. The obtained DG will be located in the system so that developing a new staring base case with repetitive steps of placing single DG. The best select of DG sizes cannot be the optimal overall choices. It is reasonably illustrated that the optimal DG (size and placement) is optimum choice at the time of adding of each DG, but not for the overall complete system. However, the optimum overall global DG size choices are detected by using algorithms provided that the placement of DGs which are strongminded by single algorithms of placing DGs.

\subsubsection{Identifying the global optimal DG sources sizes}

The common procedure for obtaining the optimal sizing of multi-DG connecting is as follows:

1) Input probable buses that are the best optimal DG locations are given by single placement of DG and applying genetic algorithm again.

2) In a random way selecting the initial GA population.

3) Applying the power flow for the DSC with the existing of the injected DG at the best optimal location.

4) Assess the needed objective function by the power flow with the existing of the inserted DG from the GA search.

5) Repeating steps 3, 4 for all groupings populations of GA.

6) Giving values to the objective function as a fitness to GA.

7) Checking the criteria of GA convergence if it's satisfied then goes to step no 9.

8) Generating one a new generation and then go to step no 3.

9) Printing the result for all probable candidate buses.

\subsubsection{Optimal sites and sizes of DG using GA}

This process is repetitive for multiple locations and sizes of DGs. By using GA, simply we can obtain both the optimal site and size for the following cases:

a) Consider existing of $1 \mathrm{DG}$.

b) Consider existing of $2 \mathrm{DG}$.

c) Consider existing of 3 DG.

\section{RESULTS AND DISCUSSION}

The test system is the standard 33 bus radial DS network given in Figure 2(a) and Figure 2(b), with number of thirty -two branches and three laterals. The reactive and real powers of the connected loads for this network are 2.3 MVAR and3.72 MW respectively. The active and reactive power losses for this radial DS network without DGs are $201.893 \mathrm{~kW}$ and $134.641 \mathrm{kVAR}$ respectively.

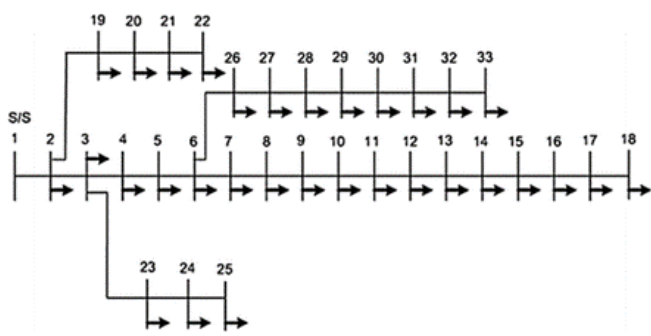

(a)

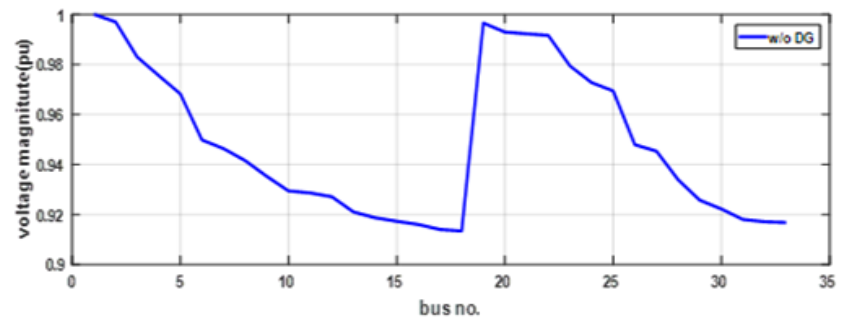

(b)

Figure 2. The test system is the standard 33 bus radial DS network: (a) single line diagram of standard IEEE 33 bus DS and (b) magnitude of the node voltage of base case of 33-bus test DS

\subsection{Using single objective function of transmission efficiency \\ 4.1.1. Optimum size DGs}

Assuming DG location as follows:

a) Existing one DG at bus 6 as it is the longest branch and near to load center.

b) The results as shown in Table 1 are approximately equal between optimization techniques and the optimal size is $2588 \mathrm{kw}$ at bus 6 .

c) Existing two DG at bus 6 and 18 as it is near to load center and the end node of the longest branch.

d) The results as shown in Table 1 show the optimal size to achieve maximum transmission is $2079 \mathrm{kw}$ at 
bus 6 and $462 \mathrm{kw}$ at bus 18 .

e) Existing $3 \mathrm{DG}$ at bus 6.18 , and 33 near to load center, the end node of the longest branch, and second far end node at the second-largest branch.

f) The results as shown in Table 1 are the optimum size, in this case, obtained by GWO or WOA is $1396 \mathrm{kw}$ at bus $6,457 \mathrm{kw}$ at bus 18 , and $658 \mathrm{kw}$ at bus 33 .

Before installing the DG, the voltage profiles of some of the buses in all distribution systems exceed the required constraint limitations. As a result, after using the genetic algorithm to identify the ideal size DG as the base technique, the voltage profile of all buses in all systems moved to the suitable range, as shown in Figure 3(a). After adding DG sources, there is the increase in the system's transmission efficiency. Compared to single DG placement, the total DG capacity mounted in the device is smaller for multi DG positioning after putting the optimal DG determined by the genetic algorithm as base technique as shown in Figure 3(b).

Table 1. Global optimum size of DGs for transmission efficiency maximization

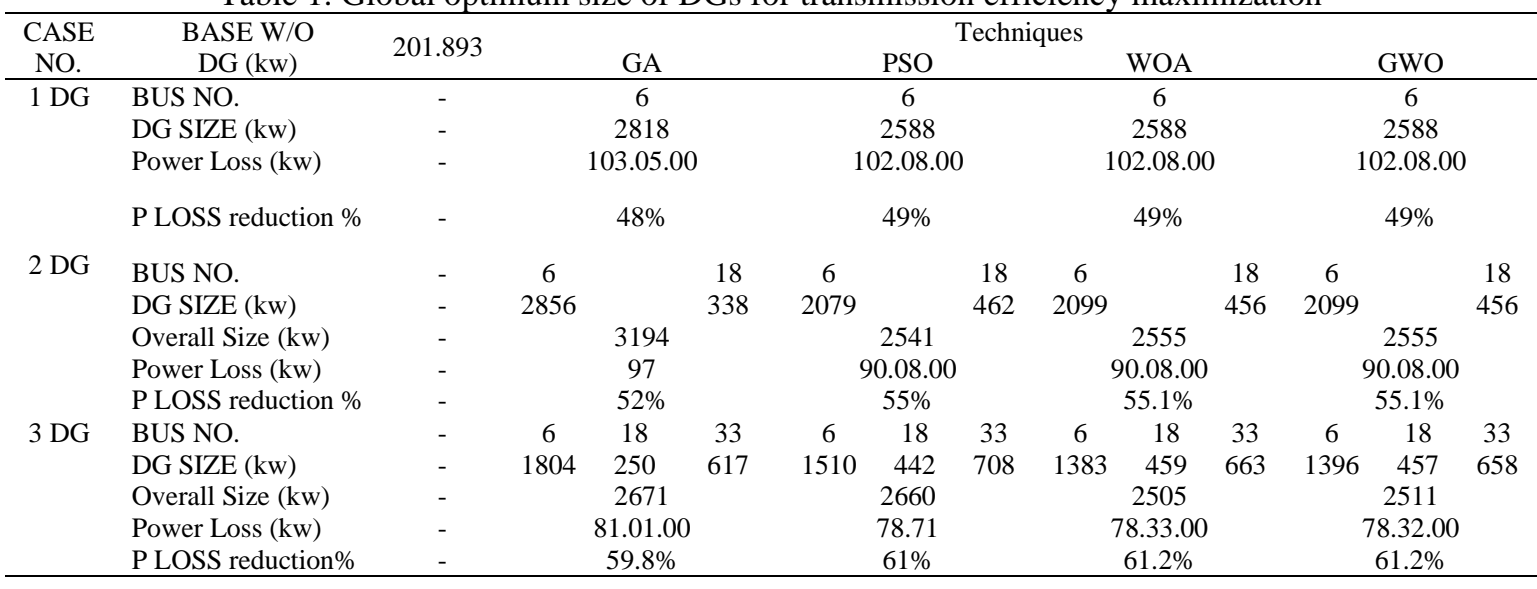

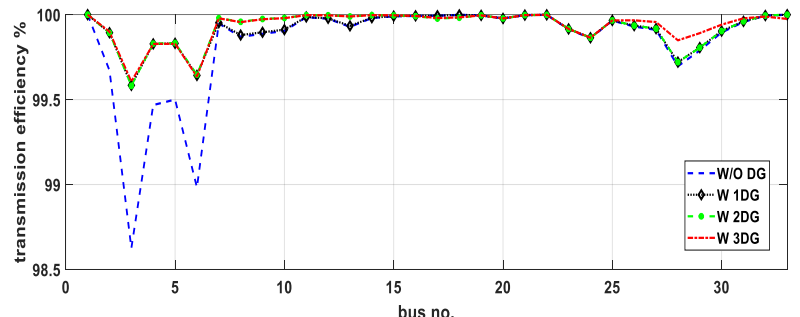

(a)

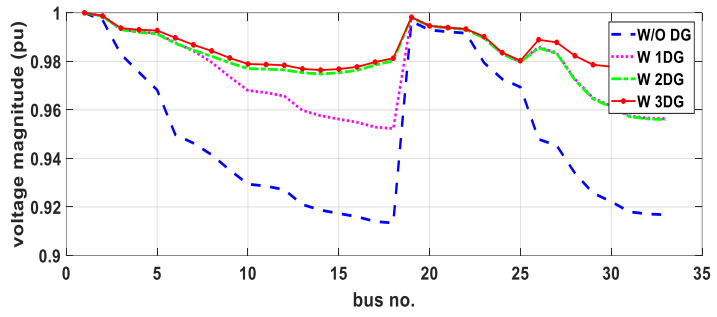

(b)

Figure 3. Optimum allocation of DGs: (a) magnitude of the node voltage and (b) transmission efficiency

\subsubsection{Optimum site DGs}

Assuming DG size from the results as follows in Table 1:

- $\quad$ Existing one DG with size $2588 \mathrm{kw}$.

- The results are witten in Table 2 are approximately equal between optimization techniques and the optimal site is bus 6 . The loss reduction percentage, in this case, is $49 \%$.

- $\quad$ Existing two DG with size $2079 \mathrm{kw}$ and $462 \mathrm{kw}$ as in WOA.

- $\quad$ The results are shown in Table 2 illustrate the optimal site to achieve maximum transmission at bus 6 and bus 18 . The loss reduction percentage, in this case, is $55.6 \%$.

- $\quad$ Existing 3DG for example from different techniques with sizes 1510, 442, and $708 \mathrm{kw}$ as in PSO.

- The results shown in Table 2 are the optimum site at bus 29, bus 16, and bus 25. The loss reduction percentage, in this case, is $62.4 \%$.

Before installing the DG, the voltage profiles of some buses in the distribution system exceed the required constraint limitations. As a result, after using the different optimization algorithmes to identify the optimum site DG for the three cases (1 DG, 2 DG, and 3 DG). The voltage profile of all buses in all systems moved to the suitable range, as shown in Figure 4(a). There is the increase in the system's transmission 
efficiency after adding DG sources, when compared to the base case without DG and the single DG installation. After using the genetic algorithm to select the optimum DG site, as shown in Figure 4(b).

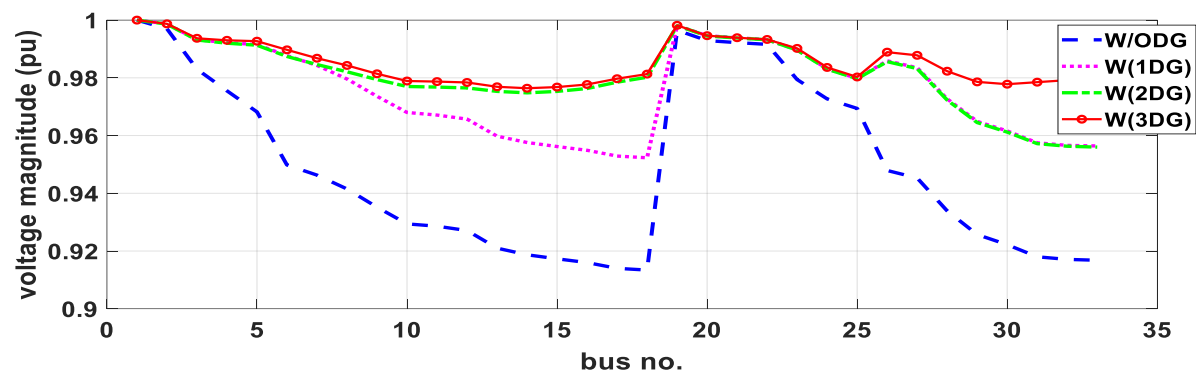

(a)

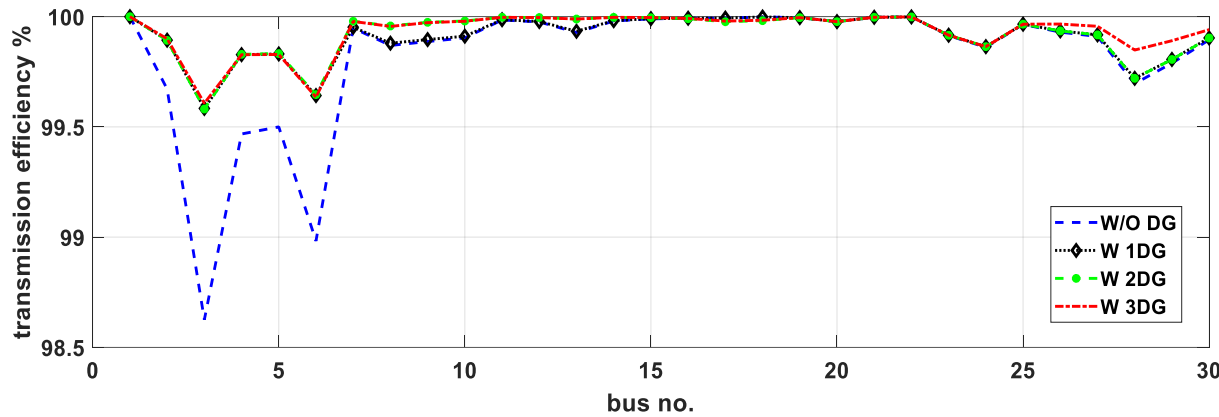

(b)

Figure 4. Optimum site of DGs: (a) magnitude of the node voltage and (b) transmission efficiency

Table 2. Global optimum site of DGs for transmission efficiency maximization

\begin{tabular}{|c|c|c|c|c|c|c|c|c|c|c|c|c|c|c|}
\hline \multirow{2}{*}{$\begin{array}{l}\text { CASE } \\
\text { NO. }\end{array}$} & \multirow{2}{*}{$\begin{array}{c}\text { BASE W/O DG } \\
(\mathrm{kw})\end{array}$} & \multirow{2}{*}{201.893} & \multicolumn{12}{|c|}{ Techniques } \\
\hline & & & \multicolumn{3}{|c|}{ GA } & \multicolumn{2}{|r|}{$\frac{\text { PSO }}{2588}$} & & \multicolumn{3}{|c|}{ WOA } & \multicolumn{3}{|c|}{ GWO } \\
\hline \multirow{2}{*}{ IDG } & BUS NO. & - & \multicolumn{3}{|c|}{6} & \multicolumn{3}{|c|}{6} & \multicolumn{3}{|c|}{6} & \multicolumn{3}{|c|}{6} \\
\hline & $\begin{array}{l}\text { P LOSS reduction } \\
\%\end{array}$ & - & \multicolumn{3}{|c|}{$48 \%$} & & $49 \%$ & & \multicolumn{3}{|c|}{$49 \%$} & \multicolumn{3}{|c|}{$49 \%$} \\
\hline \multirow[t]{3}{*}{$2 \mathrm{DG}$} & DG SIZE (kw) & - & 2856 & & 338 & 2079 & & 462 & 2079 & & 462 & 2079 & & 462 \\
\hline & Power Loss (kw) & - & \multicolumn{3}{|c|}{$\begin{array}{c}3194 \\
96.07 .00\end{array}$} & \multicolumn{3}{|c|}{89.07 .00} & \multicolumn{3}{|c|}{$\begin{array}{c}2541 \\
89.06 .00\end{array}$} & \multicolumn{3}{|c|}{91.02 .00} \\
\hline & $\begin{array}{l}\text { P LOSS reduction } \\
\%\end{array}$ & - & $51.9 \%$ & & & & $55.5 \%$ & & $55.6 \%$ & & & & $54.8 \%$ & \\
\hline \multirow[t]{3}{*}{$3 \mathrm{DG}$} & DG SIZE (kw) & - & 1804 & 250 & 617 & 1510 & 442 & 708 & 459 & 663 & 1383 & 1396 & 457 & 658 \\
\hline & BUS NO. & - & 6 & 17 & 31 & 29 & 16 & 25 & 14 & 25 & 30 & 7 & 15 & 31 \\
\hline & Overall Size (kw) & - & \multicolumn{3}{|c|}{2671} & \multicolumn{3}{|c|}{2660} & \multicolumn{3}{|c|}{2505} & \multicolumn{3}{|c|}{2511} \\
\hline
\end{tabular}

\subsubsection{Optimum allocation of DGs}

This section looks at the problem for one, two, and three DGs existing. The different techniques determine the appropriate position of the DG unit, in addition to its size. But the previous sections determine the size only or position of the units. The results of this section are summarized in Table 3 . The voltage profile of all buses is enhanced and is within the acceptable range in all three cases (after inserting the optimum location and capacity of the one, two, and three DG units) as shown in Figure 5(a). It illustrates that the better voltage profile, the greater the number of DG units. The increasing in the system's transmission efficiency after adding DG sources is shown in Figure 5(b). 
Table 3. Global Optimum allocation of DGs for transmission efficiency maximization

\begin{tabular}{|c|c|c|c|c|c|c|c|c|c|c|c|c|c|c|}
\hline \multirow{2}{*}{$\begin{array}{l}\text { CASE } \\
\text { NO. }\end{array}$} & \multirow{2}{*}{$\begin{array}{c}\text { BASE W/O } \\
\text { DG }(k w)\end{array}$} & \multirow{2}{*}{201.893} & \multicolumn{12}{|c|}{ Techniques } \\
\hline & & & \multicolumn{3}{|c|}{ GA } & \multicolumn{3}{|c|}{ PSO } & \multicolumn{3}{|c|}{ WOA } & \multicolumn{3}{|c|}{ GWO } \\
\hline \multirow[t]{4}{*}{ I DG } & DG SIZE (kw) & - & \multicolumn{3}{|c|}{2588} & \multicolumn{3}{|c|}{2455} & \multicolumn{3}{|c|}{2588} & \multicolumn{3}{|c|}{2588} \\
\hline & BUS NO. & - & & 6 & & \multicolumn{3}{|c|}{26} & \multicolumn{3}{|c|}{6} & \multicolumn{3}{|c|}{6} \\
\hline & $\begin{array}{l}\text { Power Loss } \\
(\mathrm{KW})\end{array}$ & - & & 102.08 & & \multicolumn{3}{|c|}{104.03} & \multicolumn{3}{|c|}{102.08} & \multicolumn{3}{|c|}{102.08} \\
\hline & $\begin{array}{l}\mathrm{P} \text { LOSS } \\
\text { reduction \% }\end{array}$ & - & & $49 \%$ & & \multicolumn{3}{|c|}{$48.3 \%$} & \multicolumn{3}{|c|}{$49 \%$} & \multicolumn{3}{|c|}{$49 \%$} \\
\hline \multirow[t]{5}{*}{$2 \mathrm{DG}$} & DG SIZE (kw) & - & 1192 & & 850 & 850 & \multicolumn{2}{|c|}{1192} & \multicolumn{2}{|c|}{850} & 1192 & 1000 & & \multirow{5}{*}{$\begin{array}{c}1126 \\
30\end{array}$} \\
\hline & BUS NO. & - & 13 & & 30 & 13 & 3 & & & 14 & 30 & 12 & & \\
\hline & $\begin{array}{l}\text { Overall Size } \\
(\mathrm{kw})\end{array}$ & - & & 2042 & & \multicolumn{3}{|c|}{2042} & \multicolumn{3}{|c|}{2042} & \multicolumn{2}{|r|}{2126} & \\
\hline & $\begin{array}{l}\text { Power Loss } \\
(\mathrm{KW})\end{array}$ & - & & 82.09 & & \multicolumn{3}{|c|}{82.09 .00} & \multicolumn{3}{|c|}{83} & \multicolumn{2}{|r|}{83.02 .00} & \\
\hline & $\begin{array}{l}\text { P LOSS } \\
\text { reduction \% }\end{array}$ & - & $59 \%$ & & & & $59 \%$ & & \multicolumn{2}{|c|}{$58.9 \%$} & & \multicolumn{2}{|r|}{$58.8 \%$} & \\
\hline $3 \mathrm{DG}$ & DG SIZE (kw) & - & 725 & 1070 & 1119 & 759 & 1071 & 1100 & 759 & 1071 & 1100 & 1383 & 1000 & 1000 \\
\hline & BUS NO. & - & 14 & 24 & 30 & 14 & 24 & 30 & 15 & 24 & 31 & 3 & 12 & 30 \\
\hline & $\begin{array}{l}\text { Overall Size } \\
(\mathrm{kw})\end{array}$ & - & & 2914 & & & $\begin{array}{c}293 \\
0\end{array}$ & & & 2930 & & & 3383 & \\
\hline & $\begin{array}{l}\text { Power Loss } \\
\text { (KW) }\end{array}$ & - & & 69.04 & & & 69.4 & & & 71.03 & & & 76.06 & \\
\hline & $\begin{array}{l}\text { P LOSS } \\
\text { reduction \% }\end{array}$ & - & & $\begin{array}{c}65.6 \\
\%\end{array}$ & & & $\begin{array}{c}56.6 \\
\%\end{array}$ & & & $64.8 \%$ & & & $62 \%$ & \\
\hline
\end{tabular}

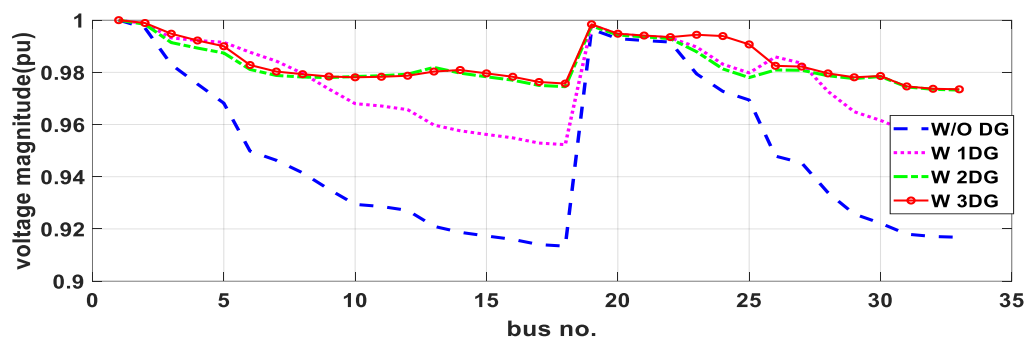

(a)

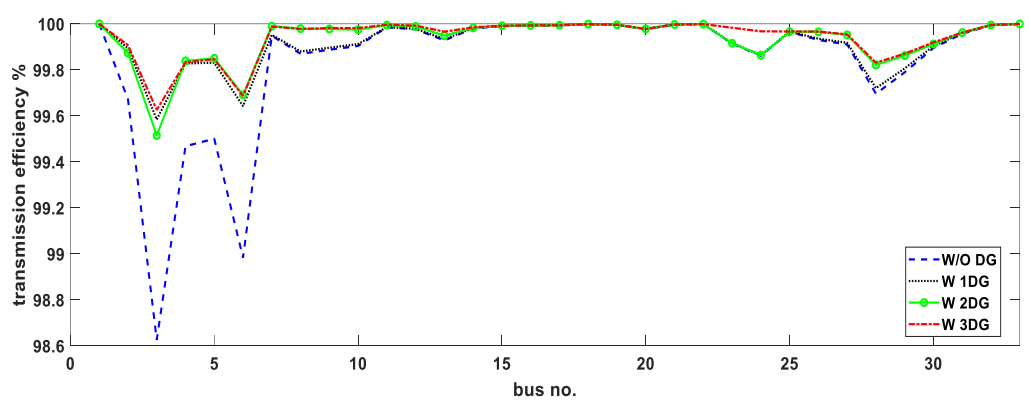

(b)

Figure 5. Global optimum allocation of DGs: (a) magnitude of the node voltage and (b) transmission efficiency

\subsection{Optimum allocation of DGs and minimization of total cost as SOI}

The total cost can be minimized by selecting the optimum allocation of DGs taking into consideration the interest and inflation rate, thus we can extract the maximum profit, and certain assumptions are considered. The effect of DG placement and capacity in a 33-bus test system was demonstrated in Table 4 as a result of the simulation. The price list of DG units from generator joe company, the cost of service and maintenance are shown in Table 5, and the benefit earned during the planning period. For serval study duration, optimum positioning and size are carried out with DG. Table 4 presents the financial and technical benefits and profits of DG size and placement, based on the results of simulation by the proposed GA as base algorithm compared with other techniques of algorithms, and presents the best Global optimal location and size of DG sources for minimizing total cost in case of injecting three DGs with overall capacity $600 \mathrm{kw}$ only at bus bar $(15,18,32)$, the profit $1.5508^{*} 10^{\wedge} 6 \$$ and the loss reduction percentage $52.9 \%$ taking into consideration interest and inflation rates. In the case of injecting two DGs with an overall capacity of 400 $\mathrm{KW}$ only at the bus bar $(32,17)$, the profit $0.92471 * 10^{\wedge} 6 \$$ and the loss reduction percentage $23 \%$. In the 
case of injecting one DG with an overall capacity of $200 \mathrm{kw}$ only at the bus bar (17), the profit $0.88717^{*} 10^{\wedge} 6$ $\$$ and the loss reduction percentage $12.5 \%$.

The voltage profile is shown in Figure 6(a) as an obtained by genetic algorithm and this is the worst solution technique for optimum allocation of DGs for minimizing total cost as SOI. The values of voltage profile at some buses in the non-acceptable range. The Transmission efficiency of this case is shown in Figure 6(b). The transmission efficiency is not sufficiently improved like in previous cases, in addition to the economic profit was higher because this is from the economic point of view.

Table 4. Global optimum allocation of DGs for minimizing total cost

\begin{tabular}{|c|c|c|c|c|c|c|c|c|c|c|c|c|c|c|}
\hline \multirow{2}{*}{$\begin{array}{l}\text { CASE } \\
\text { NO. }\end{array}$} & \multirow{2}{*}{$\begin{array}{c}\text { BASE W/O DG } \\
(\mathrm{kw})\end{array}$} & \multirow{2}{*}{201.893} & \multicolumn{12}{|c|}{ Techniques } \\
\hline & & & \multicolumn{3}{|c|}{ GA } & \multicolumn{3}{|c|}{ PSO } & \multicolumn{3}{|c|}{ WOA } & \multicolumn{3}{|c|}{ GWO } \\
\hline \multirow[t]{5}{*}{ I DG } & DG SIZE (kw) & - & \multicolumn{3}{|c|}{200} & \multicolumn{3}{|c|}{200} & \multicolumn{3}{|c|}{200} & \multicolumn{3}{|c|}{200} \\
\hline & BUS NO. & - & \multicolumn{3}{|c|}{33} & \multicolumn{3}{|c|}{17} & \multicolumn{3}{|c|}{17} & \multicolumn{3}{|c|}{17} \\
\hline & Power Loss (KW) & - & \multicolumn{3}{|c|}{178.07} & \multicolumn{3}{|c|}{176.06} & \multicolumn{3}{|c|}{176.06} & \multicolumn{3}{|c|}{176.06} \\
\hline & P LOSS reduction \% & - & \multicolumn{3}{|c|}{$11.5 \%$} & \multicolumn{3}{|c|}{$12.5 \%$} & \multicolumn{3}{|c|}{$12.5 \%$} & \multicolumn{3}{|c|}{$12.5 \%$} \\
\hline & Profit $* 10^{\wedge} 6$ & - & \multicolumn{3}{|c|}{0,613194444} & \multicolumn{3}{|c|}{0,615972222} & \multicolumn{3}{|c|}{0,615972222} & \multicolumn{3}{|c|}{0,615972222} \\
\hline \multirow[t]{5}{*}{$2 \mathrm{DG}$} & DG SIZE (kw) & - & 200 & 20 & & 200 & & & & & 200 & 200 & & \\
\hline & BUS NO. & - & 17 & 1 & & 17 & & & & 7 & 33 & 32 & 1 & \\
\hline & Power Loss (KW) & - & \multicolumn{3}{|c|}{167.05} & \multicolumn{3}{|c|}{155.02} & \multicolumn{3}{|c|}{155.03} & & 155.02 & \\
\hline & P LOSS reduction \% & - & & $17 \%$ & & & $23.2 \%$ & & & 23.19 & & & $23.2 \%$ & \\
\hline & Profit $* 10^{\wedge} 6$ & & & 0.90324 & & & 0.9247 & & & 0.9246 & & & 0.9247 & \\
\hline $3 \mathrm{DG}$ & DG SIZE (kw) & - & 200 & 200 & 200 & 200 & 200 & 200 & 200 & 200 & 200 & 200 & 200 & 200 \\
\hline & BUS NO. & - & 7 & 20 & 29 & 14 & 17 & 32 & 15 & 18 & 32 & 14 & 17 & 32 \\
\hline & Power Loss (KW) & - & & 164.09 & & & 137.06 & & & 95.02 & & & 137.06 & \\
\hline & P LOSS reduction $\%$ & - & & $18.3 \%$ & & & $31.9 \%$ & & & $52.9 \%$ & & & $31.9 \%$ & \\
\hline & Profit $* 10^{\wedge} 6$ & - & & 14.294 & & & 14.770 & & & 15.50 & & & 14.770 & \\
\hline
\end{tabular}

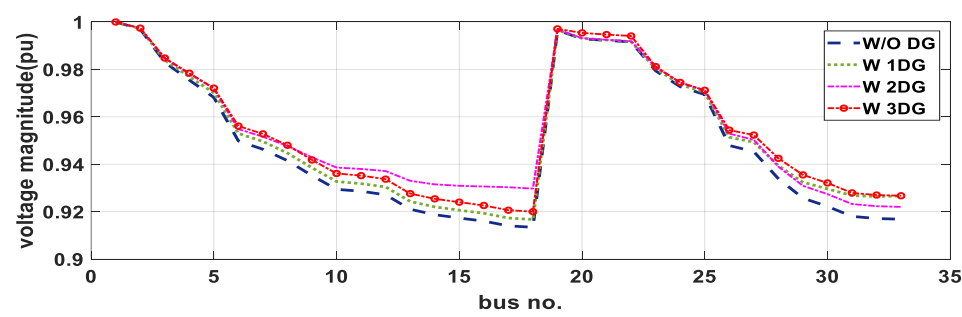

(a)

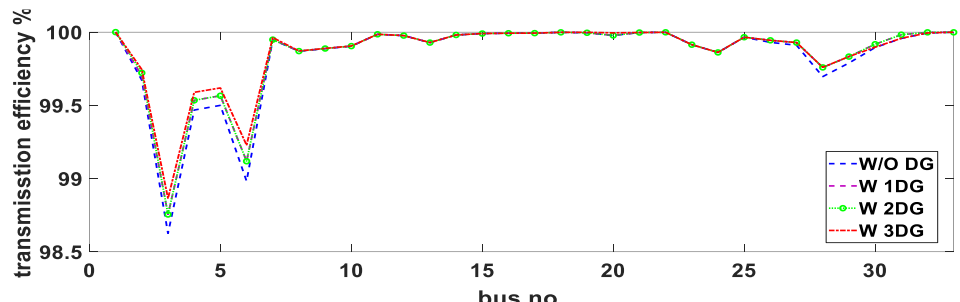

(b)

Figure 6. Optimum allocation of DGs for minimizing total cost: (a) magnitude of the node voltage and (b) transmission efficency

Table 5. The sample of price list of DG units from generator joe company

\begin{tabular}{lcccccccccc}
\hline \multirow{2}{*}{$\begin{array}{l}\text { Diesel } \\
\text { generators }\end{array}$} & Sets $60 \mathrm{HZ}$ & $200 \mathrm{KW}$ & $210 \mathrm{KW}$ & $250 \mathrm{KW}$ & $275 \mathrm{KW}$ & $280 \mathrm{KW}$ & $300 \mathrm{KW}$ & $350 \mathrm{KW}$ & $400 \mathrm{KW}$ & $450 \mathrm{KW}$ \\
\cline { 2 - 11 } $\begin{array}{l}\text { list price of } \\
\text { Generatment }\end{array}$ & $\begin{array}{c}\text { cost } \$ \text { ) } \\
\text { fuel cost }\end{array}$ & $56,705.6$ & $51,823.6$ & $53,673.9$ & $57,902.5$ & $54,310.7$ & $61,708.1$ & $65,791.3$ & $68,253.2$ & $76,978.8$ \\
joe co, & & 13.4 & $15.5 \mathrm{~g} / \mathrm{h}$ & $18.5 \mathrm{~g} / \mathrm{h}$ & $19.5 \mathrm{~g} / \mathrm{h}$ & $19.5 \mathrm{~g} / \mathrm{h}$ & $23 \mathrm{~g} / \mathrm{h}$ & $23 \mathrm{~g} / \mathrm{h}$ & $25.8 \mathrm{~g} / \mathrm{h}$ & $29.9 \mathrm{~g} / \mathrm{h}$ \\
\hline
\end{tabular}

4.2. Optimum allocation of DGs and minimization MOI of reactive power loss (Qloss), voltage deviation (VD) and maximization of transmission efficiency

It is presented as a case study in the first and then changed the weights, which the reactive power loss reduction, voltage deviation, and the transmission efficiency. Each index is assigned with different weighting factors according to their importance to get the best global performance index: 
a) Case study

From the utility point of view, is enhancing transmission efficiency to deliver energy to end-users with high transmission efficiency and high power quality. So, assume the weight factors to be W1=0.5, $\mathrm{W} 2=0.25$, and $\mathrm{W} 3=0.25$ from $(21),(22)$. When changed the weights in this case study as according to some ref [22]-[25] with optimum size and site of DGs for existence one, two, and three DGs, the results are summarized in Table 6. The voltage profile of all buses is enhanced and is within the acceptable range in three cases as shown in Figure 7(a). The transmission efficiency of optimum allocation of DGs for minimizing MOI is shown in Figure 7(b).

Table 6. Global optimum allocation of DGs for minimizing MOI

\begin{tabular}{|c|c|c|c|c|c|c|c|c|c|c|c|c|c|c|}
\hline \multirow{2}{*}{$\begin{array}{l}\text { CASE } \\
\text { NO. }\end{array}$} & \multirow{2}{*}{$\begin{array}{l}\text { BASE W/O } \\
\text { DG (kw) }\end{array}$} & \multirow{2}{*}{201.893} & \multicolumn{12}{|c|}{ Techniques } \\
\hline & & & \multicolumn{3}{|c|}{ GA } & \multicolumn{3}{|c|}{ PSO } & \multicolumn{3}{|c|}{ WOA } & \multicolumn{3}{|c|}{ GWO } \\
\hline \multirow[t]{4}{*}{ I DG } & BUS NO. & - & & & 6 & \multicolumn{3}{|c|}{6} & \multicolumn{3}{|c|}{6} & \multicolumn{3}{|c|}{6} \\
\hline & $\begin{array}{l}\text { DG SIZE } \\
(\mathrm{kw})\end{array}$ & - & & & 2959 & & 2952 & & \multicolumn{3}{|c|}{2952} & \multicolumn{3}{|c|}{2952} \\
\hline & $\begin{array}{l}\text { Power Loss } \\
\text { (KW) }\end{array}$ & - & & & 104.07 & & 104.06 & & \multicolumn{3}{|c|}{104.06} & \multicolumn{3}{|c|}{104.06} \\
\hline & $\begin{array}{l}\text { P LOSS } \\
\text { reduction\% }\end{array}$ & - & & & $48 \%$ & & $48.2 \%$ & & \multicolumn{3}{|c|}{$48.2 \%$} & \multicolumn{3}{|c|}{$48.2 \%$} \\
\hline \multirow{3}{*}{ 2DG } & $\begin{array}{l}\text { DG SIZE } \\
(\mathrm{kw})\end{array}$ & - & 991 & \multicolumn{2}{|c|}{1203} & 1270 & \multicolumn{2}{|c|}{957} & \multicolumn{2}{|c|}{957} & 1270 & 2266 & \multicolumn{2}{|c|}{563} \\
\hline & $\begin{array}{l}\text { Overall Size } \\
(\mathrm{kw})\end{array}$ & - & & & 2221 & & \multicolumn{2}{|l|}{2227} & \multicolumn{3}{|c|}{2227} & \multicolumn{3}{|c|}{2829} \\
\hline & $\begin{array}{l}\text { Power Loss } \\
(\mathrm{KW})\end{array}$ & - & & & 83.08 & 38.83 & & & \multicolumn{3}{|c|}{86.67} & \multicolumn{3}{|c|}{90.01} \\
\hline & $\begin{array}{l}\text { Overall Size } \\
(\mathrm{kw})\end{array}$ & - & & 3110 & & & 2957 & & & 3124 & & & 3083 & \\
\hline & $\begin{array}{l}\text { Power Loss } \\
(\mathrm{KW})\end{array}$ & - & & 70.03 & & & 69.05 & & & 74.07 & & & 77.05 & \\
\hline & $\begin{array}{l}\mathrm{P} \text { LOSS } \\
\text { reduction \% }\end{array}$ & - & & $65 \%$ & & & $65.6 \%$ & & & $63 \%$ & & & $61.6 \%$ & \\
\hline
\end{tabular}

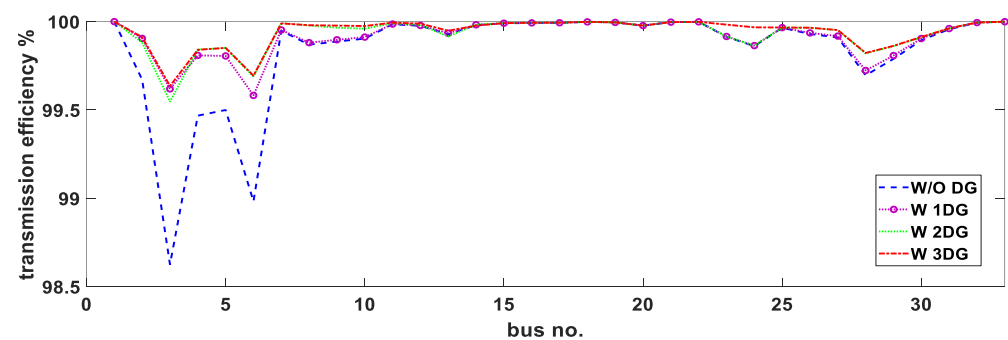

(a)

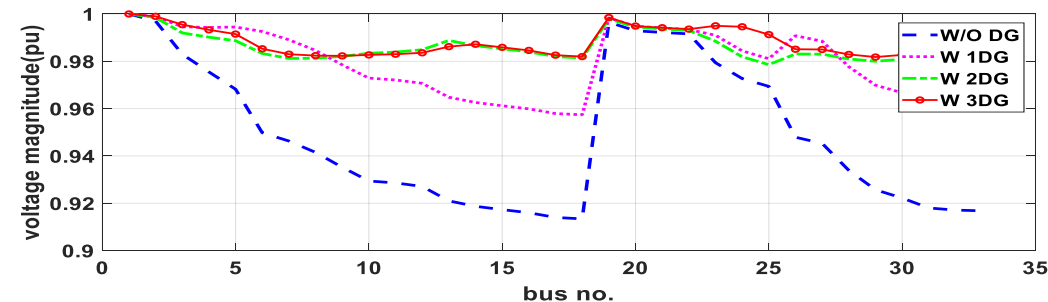

(b)

Figure 7. Optimum allocation of DGs for minimizing MOI: (a) magnitude of the node voltage and (b) transmission efficiency

b) Changing the weight factors by parito method to achieve the best MOI

- Allocation by (constant weight of transmission efficiency equal to 0.1 ) and changing other weights from 0.1 to 0.8 So that it is equal to 1 . The best case that appeared when $\mathrm{W} 1=0.1, \mathrm{~W} 2=0.1$, and $\mathrm{W} 3=0.8$, 
when allocated DGs for minimizing MOI by using this weights factor. So, the voltages profile is dominant. The end node voltage is improved and arrived at 1pu approximately because of the largest weight comparing to another weight as shown in Figure 8(a). The transmission efficiency of optimum allocation of DGs for minimizing MOI taking into consideration voltage profile is shown in Figure 8(b). When changed the weights of this case study as according to the largest problem in the grid (VD) with optimum size and site of DGs for existence one, two, and three DGs, the results are summarized in Table 7.

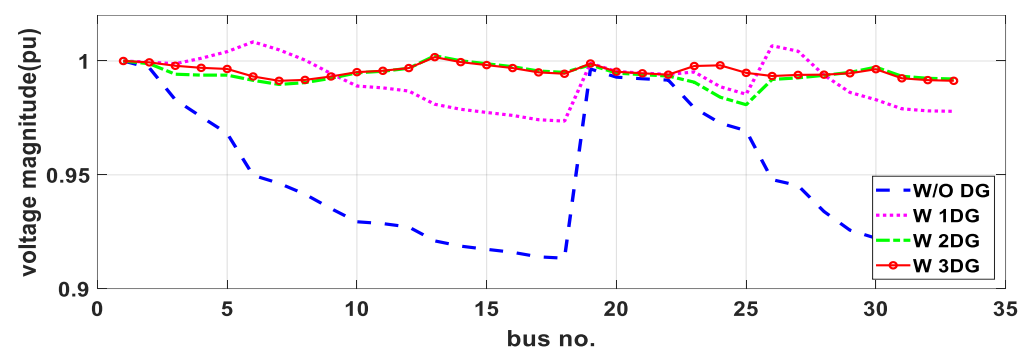

(a)

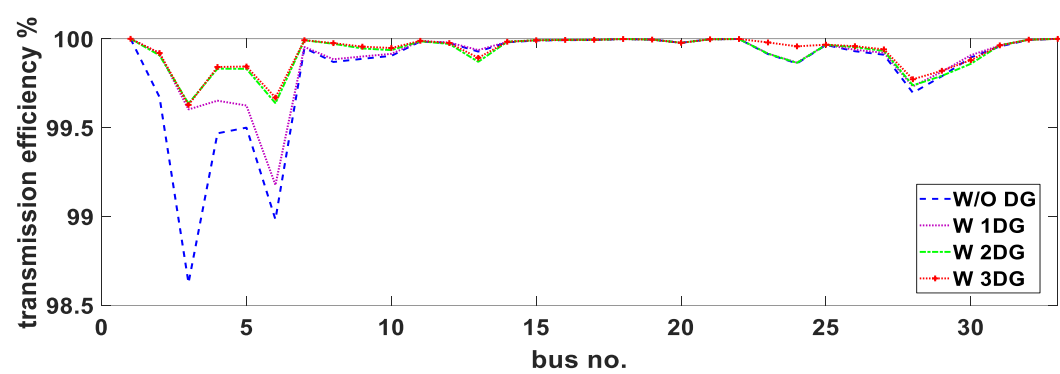

(b)

Figure 8. Optimum allocation of DGs for minimizing MOI taking into consideration voltage profile:

(a) magnitude of the node voltage and (b) transmission efficiency

Table 7. Global optimum allocation of DGs sources for minimizing MOI taking into consideration voltage profile

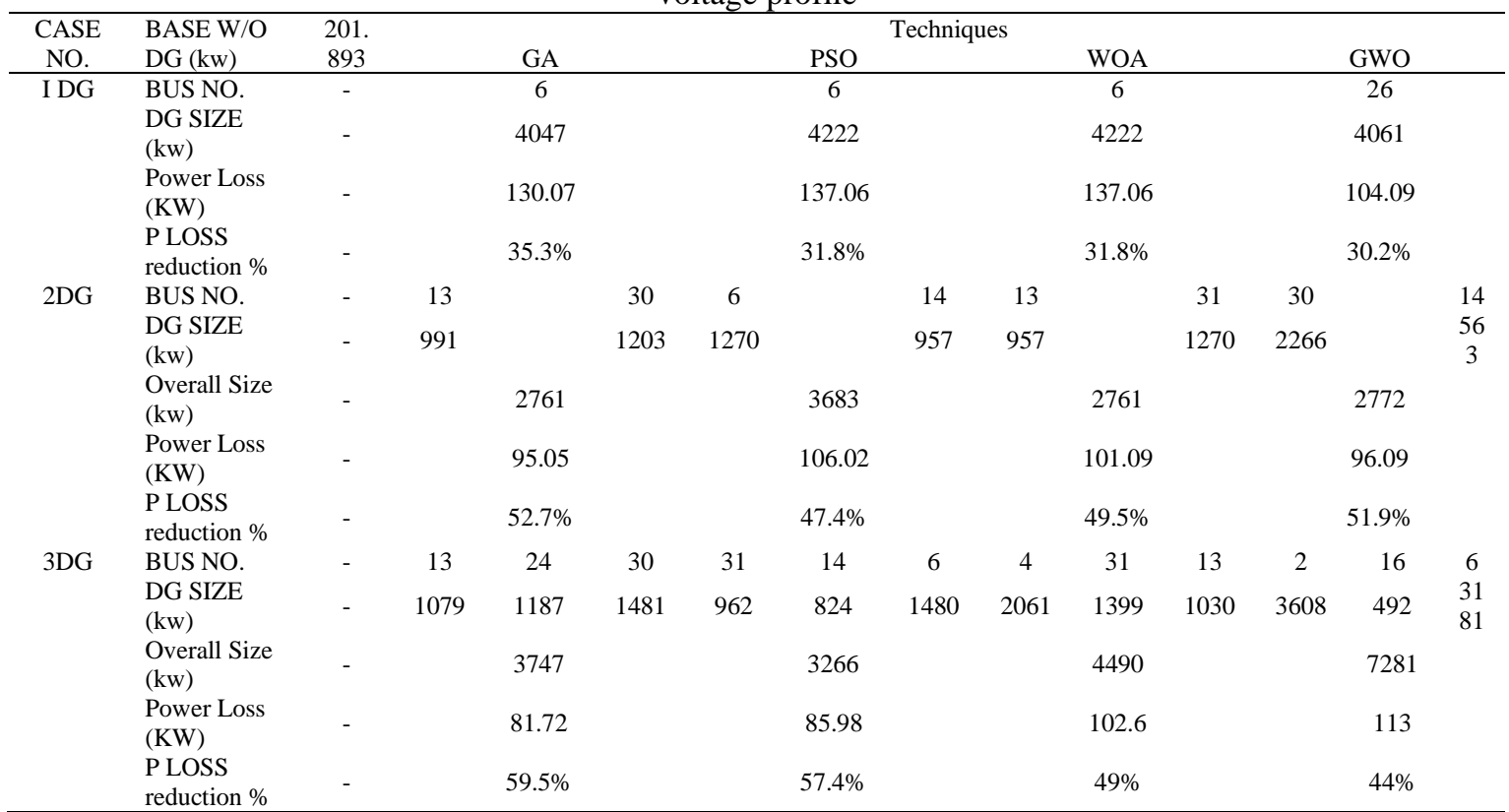

- $\quad$ Allocation by (constant weight of reactive power loss equal to 0.1 ) and changing other weights from 0.1 to 0.8 so that it is equal to 1 . The best case that appeared when $\mathrm{W} 1=0.8, \mathrm{~W} 2=0.1$, and $\mathrm{W} 3=0.1$, When 
made the penetration DG for minimizing MOI by using this weights factor. So, transmission efficiency is dominant because of the largest weight comparing to another weight. When changed the weights of this case as according to the largest problem (PL) in the grid with optimum size and site of DGs for existence one, two, and three DGs, the results are summarized in Table 8. The voltage profile of all buses is enhanced and is within the acceptable range in three cases as shown in Figure 9(a). The transmission efficiency of optimum allocation of DGs for minimizing MOI is shown in Figure 9(b).

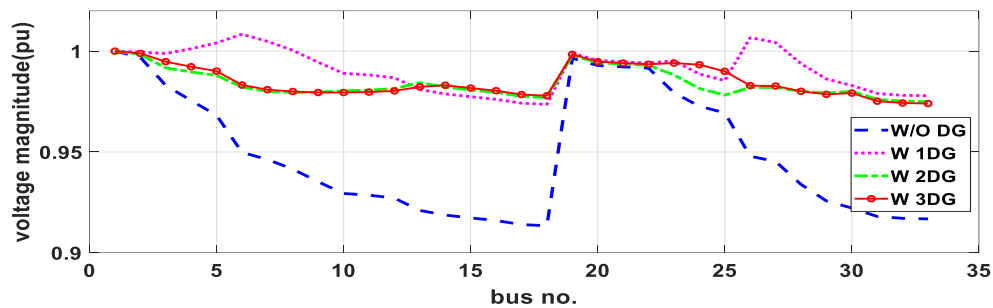

(a)

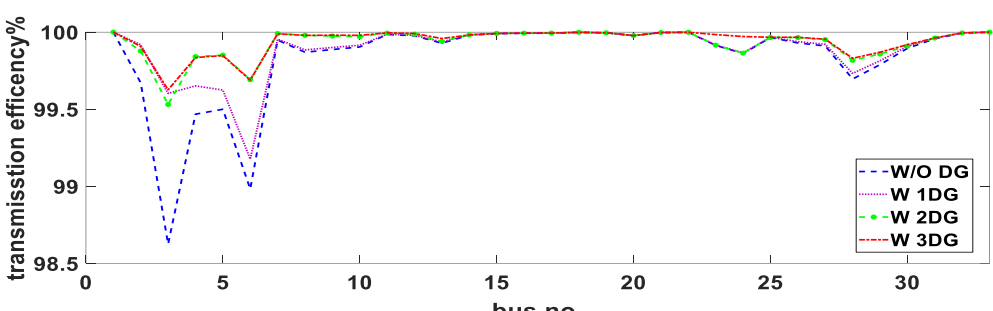

(b)

Figure 9. Optimum allocation of DGs for minimizing MOI taking into consideration maximizing transmission efficiency: (a) magnitude of the node voltage and (b) transmission efficiency

Table 8. Global optimum allocation of DGs for minimizing MOI

\begin{tabular}{|c|c|c|c|c|c|c|c|c|c|c|c|c|c|c|}
\hline \multirow{2}{*}{$\begin{array}{l}\text { CASE } \\
\text { NO. }\end{array}$} & \multirow{2}{*}{$\begin{array}{l}\text { BASE W/O } \\
\text { DG }(k w)\end{array}$} & \multirow{2}{*}{201.893} & \multicolumn{12}{|c|}{ Techniques } \\
\hline & & & \multicolumn{3}{|c|}{ GA } & \multicolumn{3}{|c|}{ PSO } & \multicolumn{3}{|c|}{ WOA } & \multicolumn{3}{|c|}{ GWO } \\
\hline \multirow[t]{4}{*}{ I DG } & BUS NO. & - & \multicolumn{3}{|c|}{6} & \multicolumn{3}{|c|}{6} & \multicolumn{3}{|c|}{6} & \multicolumn{3}{|c|}{6} \\
\hline & $\begin{array}{l}\text { DG SIZE } \\
(\mathrm{kw})\end{array}$ & - & \multicolumn{3}{|c|}{2707} & \multicolumn{3}{|c|}{2723} & \multicolumn{3}{|c|}{2723} & \multicolumn{3}{|c|}{2723} \\
\hline & $\begin{array}{l}\text { Power Loss } \\
\text { (KW) }\end{array}$ & - & \multicolumn{3}{|c|}{102.09} & \multicolumn{3}{|c|}{103} & \multicolumn{3}{|c|}{103} & \multicolumn{3}{|c|}{103} \\
\hline & $\begin{array}{l}\mathrm{P} \text { LOSS } \\
\text { reduction \% }\end{array}$ & - & \multicolumn{3}{|c|}{$49 \%$} & & $48.9 \%$ & & \multicolumn{3}{|c|}{$48.9 \%$} & \multicolumn{3}{|c|}{$48.9 \%$} \\
\hline \multirow[t]{5}{*}{ 2DG } & BUS NO. & - & 13 & \multicolumn{2}{|c|}{30} & 30 & \multicolumn{2}{|c|}{13} & \multicolumn{2}{|r|}{13} & 30 & 27 & \multicolumn{2}{|c|}{14} \\
\hline & $\begin{array}{l}\text { DG SIZE } \\
(\mathrm{kw})\end{array}$ & - & 893 & \multicolumn{2}{|c|}{1222} & 1222 & \multicolumn{2}{|c|}{893} & \multicolumn{2}{|r|}{893} & 1222 & 1823 & \multicolumn{2}{|c|}{638} \\
\hline & $\begin{array}{l}\text { Overall } \\
\text { Size (kw) }\end{array}$ & - & \multicolumn{3}{|c|}{2115} & & 2115 & & & 2115 & & & 2461 & \\
\hline & $\begin{array}{l}\text { Power Loss } \\
\text { (KW) }\end{array}$ & - & & 83.01 .00 & & & 83.01 & & & 83.01 & & & 88.03 & \\
\hline & $\begin{array}{l}\text { P LOSS } \\
\text { reduction \% }\end{array}$ & - & & $58.9 \%$ & & & $58.9 \%$ & & & $58.9 \%$ & & & $56.3 \%$ & \\
\hline 3DG & BUS NO. & - & 14 & 24 & 30 & 14 & 30 & 3 & 14 & 25 & 30 & 14 & 30 & 25 \\
\hline & $\begin{array}{l}\text { DG SIZE } \\
(\mathrm{kw})\end{array}$ & - & 797 & 1000 & 1124 & 770 & 1083 & 1626 & 797 & 1075 & 1134 & 911 & 1071 & 464 \\
\hline & $\begin{array}{l}\text { Overall } \\
\text { Size (kw) }\end{array}$ & - & & 2921 & & & 3479 & & & 3006 & & & 2446 & \\
\hline & $\begin{array}{l}\text { Power Loss } \\
\text { (KW) }\end{array}$ & - & & 69.52 & & & 75.06 & & & 70.85 & & & 73.03 & \\
\hline & $\begin{array}{l}\text { P LOSS } \\
\text { reduction \% }\end{array}$ & - & & $65.6 \%$ & & & $62.8 \%$ & & & $64.9 \%$ & & & $63.7 \%$ & \\
\hline
\end{tabular}

- $\quad$ Allocation by (Constant weight of voltage deviation equal to 0.1 ) and changing other weights from 0.1 to 0.8 so that it is equal to 1 . The best case that appeared when $\mathrm{W} 1=0.1, \mathrm{~W} 2=0.8$, and $\mathrm{W} 3=0.1$, When made the penetration DG for minimizing MOI by using this weights factor. So, reactive power loss is the dominant because of the largest weight comparing to other weights. The voltage profile of all buses is enhanced and is within the acceptable range in three cases as shown in Figure 10(a). The transmission 
efficiency of optimum allocation of DGs for minimizing MOI is shown in Figure 10(b). When changed the weights of this case as according to the largest problem (QL) in the grid with optimum size and site of DGs for existence one, two, and three DGs, the results are summarized in Table 9.

Table 9. Global optimum allocation of DGs for minimizing MOI taking into consideration reactive power

\begin{tabular}{|c|c|c|c|c|c|c|c|c|c|c|c|c|c|c|}
\hline CASE & BASE W/O & 201.89 & \multicolumn{12}{|c|}{ Techniques } \\
\hline \multirow{2}{*}{ I DG } & DG SIZE (kw) & - & \multicolumn{3}{|c|}{2710} & \multicolumn{3}{|c|}{2676} & \multicolumn{3}{|c|}{2676} & \multicolumn{3}{|c|}{2675} \\
\hline & $\begin{array}{l}\mathrm{P} \text { LOSS } \\
\text { reduction \% }\end{array}$ & - & \multicolumn{3}{|c|}{$48.9 \%$} & & $49 \%$ & & \multicolumn{3}{|c|}{$49 \%$} & \multicolumn{3}{|c|}{$49 \%$} \\
\hline \multirow[t]{4}{*}{$2 \mathrm{DG}$} & BUS NO. & - & 13 & \multicolumn{2}{|c|}{$\begin{array}{c}30 \\
1170\end{array}$} & 30 & \multicolumn{2}{|c|}{13} & \multicolumn{2}{|c|}{$\begin{array}{c}13 \\
900\end{array}$} & 30 & 6 & \multicolumn{2}{|c|}{$\begin{array}{c}3 \\
1627\end{array}$} \\
\hline & $\begin{array}{l}\text { Overall Size } \\
(\mathrm{kw})\end{array}$ & - & \multicolumn{3}{|c|}{2070} & \multicolumn{3}{|c|}{1970} & \multicolumn{3}{|c|}{2070} & \multicolumn{3}{|c|}{4096} \\
\hline & $\begin{array}{l}\text { Power Loss } \\
(\mathrm{KW})\end{array}$ & - & \multicolumn{3}{|c|}{82.09} & \multicolumn{3}{|c|}{38.03} & \multicolumn{3}{|c|}{82.09} & \multicolumn{3}{|c|}{100.09} \\
\hline & $\begin{array}{l}\mathrm{P} \text { LOSS } \\
\text { reduction \% }\end{array}$ & - & \multicolumn{3}{|c|}{$58.9 \%$} & & $58.7 \%$ & & & $58.9 \%$ & & & $50 \%$ & \\
\hline & $\begin{array}{l}\text { P LOSS } \\
\text { reduction \% }\end{array}$ & - & & $65.5 \%$ & & & $65.5 \%$ & & & $\begin{array}{c}62.2 \\
\%\end{array}$ & & & $53.9 \%$ & \\
\hline
\end{tabular}

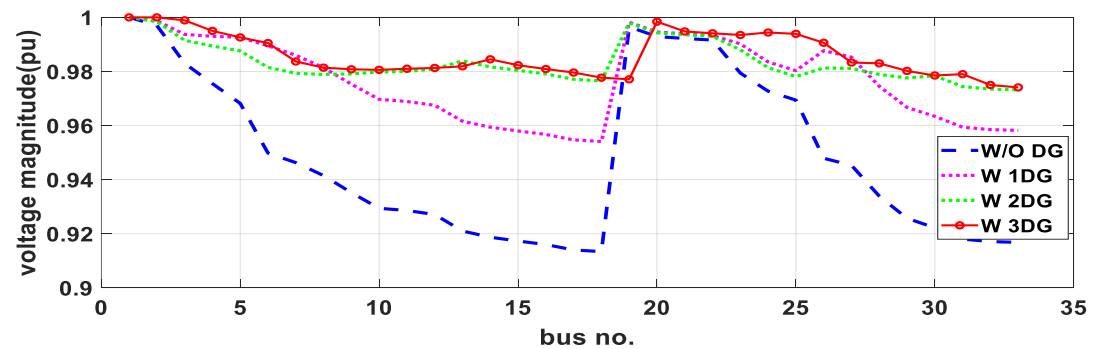

(a)

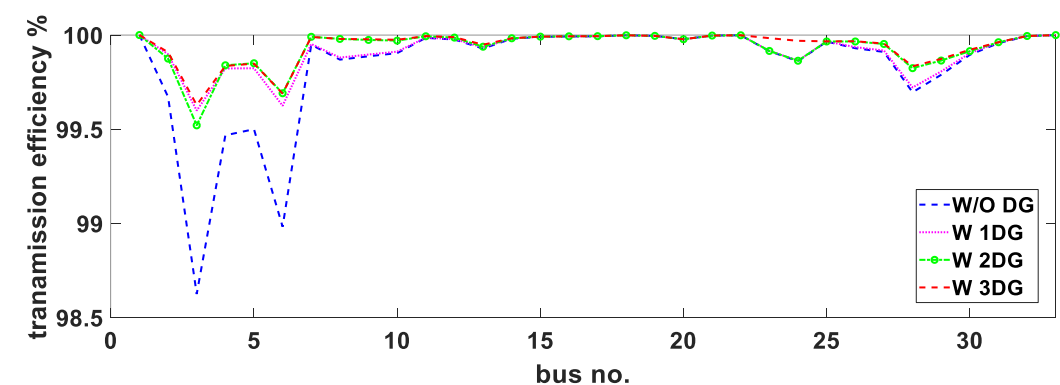

(b)

Figure 10. Optimum placement and size for minimizing MOI taking into consideration reactive power: (a) magnitude of the node voltage and (b) transmission efficiency

\section{CONCLUSION}

This paper has introduced an intensive review for obtaining the optimal DG Site, Size and Penetration between them for single and multiple DGs to fulfill economic, environmental and technical benefits using single and Multi objective indices based on a comparison between the best performance existed by GA, PSO, GWO, and WOP algorithms. The proposed algorithm techniques were tested on 33-bus radial DS and the results can be summarized as presented.

By Allocating DG units at the optimal location the system loadability is enhanced. The voltage profile is enhanced at all nodes in which DG units are best located while compared to the case that no 
allocation for DG units. While increasing the DGs penetration level, at a Particular point the increasing in reduction of losses is not much noticeable when compared to the cost increase due to this highly penetration level. The GWO has presented the best Global optimal location and size of DG sources for minimizing total cost in case of injecting three DGs taking into consideration interest and inflation rates.

\section{REFERENCES}

[1] M. M. Aman, G. B. Jasmon, A. H. A. Bakar, and H. Mokhlis, "Optimum network reconfiguration based on maximization of system loadability using continuation power flow theorem," International journal of electrical power \& energy systems, vol. 54, pp. 123-133, 2014, doi: 10.1016/j.ijepes.2013.06.026.

[2] S. Kalambe, and G. Agnihotri, "Loss minimization techniques used in distribution network: bibliographical survey," Renewable and sustainable energy reviews, vol. 29, pp. 184-200, 2014, doi: 10.1016/j.rser.2013.08.075.

[3] L. Ramesh, S. P. Chowdhury, S. Chowdhury, Y. H. Song, and A. A. Natarajan, "Voltage stability analysis and real power loss reduction in distributed distribution system," In 2008 IEEE/PES Transmission and Distribution Conference and Exposition, 2008, pp. 1-6, doi: 10.1109/TDC.2008.4517070.

[4] D. Q. Hung, and N. Mithulananthan, "Loss reduction and loadability enhancement with DG: A dual-index analytical approach," Applied energy, vol. 115, pp. 233-241, 2014, doi: 10.1016/j.apenergy.2013.11.010.

[5] D. Singh, D. Singh, and K. S. Verma, "GA based energy loss minimization approach for optimal sizing \& placement of distributed generation," International Journal of Knowledge-based and Intelligent Engineering Systems, vol. 12, no. 2, pp. 147-156, 2008, doi: 10.3233/KES-2008-12206.

[6] D. A. Amon, "A modified bat algorithm for power loss reduction in electrical distribution system," Indonesian Journal of Electrical Engineering and Computer Science (IJEECS), vol. 14, no. 1, pp. 55-61, 2015, doi: 10.11591/telkomnika.v14i1.7629.

[7] A. A. J. Jeman, N. M. S. Hannoon, N. Hidayat, M. M. H. Adam, I. Musirin, and V. Vijayakumar, "Active and reactive power management of grid connected photovoltaic system," Indonesian Journal of Electrical Engineering and Computer Science (IJEECS), vol. 13, no. 3, pp. 1324-1331, 2019, doi: 10.11591/ijeecs.v13.i3.pp1324-1331.

[8] D. Q. Hung, N. Mithulananthan, and R. C. Bansal, "Analytical expressions for DG allocation in primary distribution networks," IEEE Transactions on energy conversion, vol. 25, no. 3, pp. 814-820, 2010, doi: 10.1109/TEC.2010.2044414.

[9] I. S. Kumar and N. P. Kumar. "Optimal planning of distributed generation for improved voltage stability and loss reduction," International Journal of Computer Applications, vol. 15, no. 1, pp. 40-46, 2011, doi: 10.5120/1910-2545.

[10] R. P. Payasi, A. K. Singh, and D. Singh, "Review of distributed generation planning: objectives, constraints, and algorithms," International journal of engineering, science and technology, vol. 3, no. 3, 2011, doi: 10.4314/ijest.v3i3.68430.

[11] H. Yassami, A. Moeini, S. M. R. Rafiei, A. Darabi, and A. Bagheri. "Optimal distributed generation planning considering reliability, cost of energy and power loss," Scientific research and essays, vol. 6, no. 9, pp. 1963-1976, 2011, doi: $10.5897 /$ SRE10.955.

[12] H. Samet, "Optimal allocation of fault current limiters and distributed generations in the presence of remote controllable switches," J. Electrical Systems, vol. 10, no. 2, pp. 149-155, 2014.

[13] M. Abdelbadea, T. A. Boghdady, and D. K. Ibrahim, "Enhancing active radial distribution networks by optimal sizing and placement of DGs using modified crow search algorithm," Indonesian Journal of Electrical Engineering and Computer Science (IJEECS), vol. 16, no. 3, pp. 1179-1188, 2019, doi: 10.11591/ijeecs.v16.i3.pp1179-1188.

[14] T. Bouktir and K. R. Guerriche, "Optimal allocation and sizing of distributed generation with particle swarm optimization algorithm for loss reduction," In International Conference and Workshop on Electronics \& Telecommunication Engineering (ICWET), 2015, pp. 59-69.

[15] R. K. Singh, and S. K. Goswami, "Optimum allocation of distributed generations based on nodal pricing for profit, loss reduction, and voltage improvement including voltage rise issue," International Journal of Electrical Power \& Energy Systems, vol. 32, no. 6, pp. 637-644, 2010, doi: 10.1016/j.ijepes.2009.11.021.

[16] M. H. Moradi and M. Abedini, "A combination of genetic algorithm and particle swarm optimization for optimal DG location and sizing in distribution systems," International Journal of Electrical Power \& Energy Systems, vol. 34, no. 1, pp. 66-74, 2012, doi: 10.1016/j.ijepes.2011.08.023.

[17] S. K. Injeti and N. P. Kumar, "A novel approach to identify optimal access point and capacity of multiple DGs in a small, medium and large scale radial distribution systems," International Journal of Electrical Power \& Energy Systems, vol. 45, no. 1, pp. 142-151, 2013, doi: 10.1016/j.ijepes.2012.08.043.

[18] M. Kowsalya, "Optimal size and siting of multiple distributed generators in distribution system using bacterial foraging optimization," Swarm and Evolutionary computation, vol. 15, pp. 58-65, 2014, doi: 10.1016/j.swevo.2013.12.001.

[19] D. Shirmohammadi, H. W. Hong, A. Semlyen, and G. X. Luo, "A compensation-based power flow method for weakly meshed distribution and transmission networks," IEEE Transactions on power systems, vol. 3, no. 2, pp. 753-762, 1988, doi: $10.1109 / 59.192932$.

[20] S. K. Injeti, V. K. Thunuguntla, and M. Shareef, "Optimal allocation of capacitor banks in radial distribution systems for minimization of real power loss and maximization of network savings using bio-inspired optimization algorithms," International Journal of Electrical Power \& Energy Systems, vol. 69, pp. 441-455, 2015, doi: 10.1016/j.ijepes.2015.01.040.

[21] M. Rostamzadeh, K. Valipour, S. J. Shenava, M. Khalilpour, and N. Razmjooy, "Optimal location and capacity of multidistributed generation for loss reduction and voltage profile improvement using imperialist competitive algorithm," Artificial Intelligence Research, vol. 1, no. 2, pp. 56-66, Dec. 2012, doi: 10.5430/air.v1n2p56.

[22] I. Hussain, and A. K. Roy, "Optimal distributed generation allocation in distribution systems employing modified artificial bee colony algorithm to reduce losses and improve voltage profile," IEEE-International Conference On Advances In Engineering, Science And Management (ICAESM -2012), 2012, pp. 565-570.

[23] Y. Alinejad-Beromi, M. Sedighizadeh, M. R. Bayat, and M. E. Khodayar, "Using genetic alghoritm for distributed generation allocation to reduce losses and improve voltage profile," In 2007 42nd International Universities Power Engineering Conference, 2007, doi: 10.1109/UPEC.2007.4469077.

[24] P. A. D. V. Raj, S. Senthilkumar, J. Raja, S. Ravichandran, and T. G. Palanivelu, "Optimization of distributed generation capacity for line loss reduction and voltage profile improvement using pso," Elektrika: Journal of Electrical Engineering, vol. 10, no. 2, pp. 41-48, 2008. 
[25] Z. M. Zenhom, T. A. Boghdady, and H. K. Youssef, "A Proposed Economical Based Approach for Optimal Sizing and Placement of Distributed Generation," In 2019 21st International Middle East Power Systems Conference (MEPCON), 2019, doi: 10.1109/MEPCON47431.2019.9007932.

\section{BIOGRAPHIES OF AUTHORS}

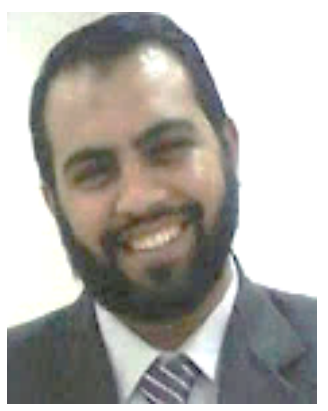

Tarek A. Boghdady (D) SC S $\mathrm{P}$ received the B. S., M. S and Ph. D degrees in electrical power engineering from the faculty of engineering Cairo University, in 2004, 2010 and 2016. From 2004 to 2016, he was a teaching assistant in electrical power engineering department in the same university. Since 2016, he has been an assistant professor in the electrical power engineering department, Cairo University. He is an author and supervisor of more than thirty scientific papers. His research interests include wind energy, optimization, power quality, neural network, fuzzy control, solar energy, sliding mode control, HVDC, and Harmonics. He can be contacted at email: Engtarek82@gmail.com.

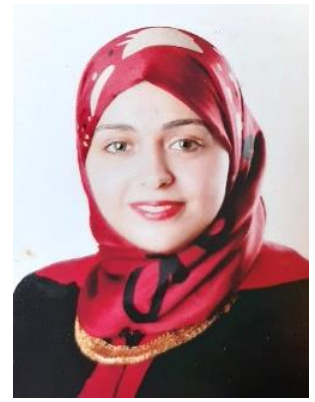

Samar G. A. Nasser (iD SC P received her B. S. degree from Institute of aviation engineering and technology (I.A.E.T), Giza, Egypt, in 2016. After graduation, she worked four years as a teaching assistant at I.A.E.T from 2016 to 2020. She is currently working towards the M. S. degree at the department of electrical power engineering at the faculty of engineering, Cairo University, Giza, Egypt. She can be contacted at email: eng_samar_gamal@yahoo.com.

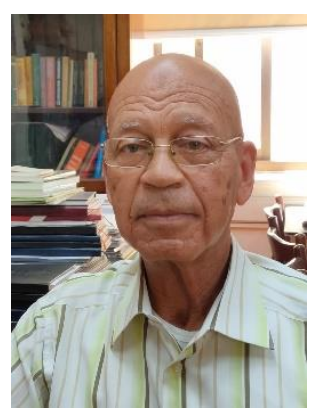

Essam El-Din Aboul Zahab (D) IS SC P received the B. S., M. S degree in electrical engineering from Cairo University, faculty of engineering in 1970, 1974 and the $\mathrm{Ph}$. D. degree in electrical engineering from Paul Sabatier University, France, in 1979. He is promoted in the academic degrees starting from teaching assistant till being professor emeritus in electri cal engineering at Cairo University. He is an author and supervisor of hundreds scientific papers. His research interest switch gear and protection, electrical distribution system, illumination engineering and electrical power systems. He can be contacted at email: Zahab0@yahoo.com. 